\title{
Community-Based Health Education and Communication Model Development for Opisthorchiasis Prevention in a High Risk Area, Khon Kaen Province, Thailand
}

\author{
Paitoon Promthet ${ }^{1}$, Pattapong Kessomboon ${ }^{1 *}$, Supannee Promthet ${ }^{2,3}$
}

\begin{abstract}
Background: This study aimed to evaluate the impact of a community-based health education and communication programme on reducing liver fluke infections caused by the consumption of uncooked fish among people in a high-risk area of Thailand. Materials and Methods: The study was quasi-experimental in nature, with three-stages. Stage 1 involved a situational and capacity analysis of designated communities in Khon Kaen province. This was followed by the development of a model for community-based health education and communication to prevent liver fluke infections among high-risk people, and, lastly, implementation and evaluation of the model were performed. Data were collected using both qualitative and quantitative methods. In total, 390 people were surveyed, and quasi-experimental and comparison groups, each with 90 people, were assessed between May 2011 and April 2012. Analysis was using statistical OR,95 \% CI, the Willcoxon matched pairs signed ranks test, the chi-square test, and the Mann-Whitney $U$ test. Results: The findings showed that most respondents had a high level of knowledge and understanding of liver fluke disease (89.5\%,95\% CI:86.0-92.4), and positive attitudes toward the prevention of the disease (94.4\%, 95\% CI:91.6-96.4). However, with regard to changes in consumption of uncooked fish, most respondents were still in the pre-contemplation phase $(55.1 \%$, 95\% CI:50.0-60.1), followed by the contemplation phase, 22.6\%. Furthermore, four factors were found to be associated with the consumption of uncooked fish - the consumption of alcohol (OR 4.16, 95\% CI:1.79-9.65), gender (OR 3.17, 95\% CI:1.53-6.54), smoking (OR 3.03, 95\% CI:1.31-7.05), and age 40 years and above (OR $2.68,95 \%$ CI:1.02-7.05). After nine months of the health education and communication programme using local media based on local wisdom, culture and persons, the results showed that, compared to the control group, members of the experimental group had a higher level of knowledge, a better attitude and lower levels of illadvised consumption behaviour. Also, it was found that consumption of uncooked fish, by an assessment of the level of stage of change, was reduced. (p-value 0.002). Conclusions: The health education and communication programme developed as part of the study was effective in changing the consumption of uncooked fish. Therefore, this approach should be promoted in other high-risk areas in Thailand in the future.
\end{abstract}

Keywords: Opisthorchiasis - health education - raw fish eating - stage of change

Asian Pac J Cancer Prev, 16 (17), 7789-7794

\section{Introduction}

Food-borne trematodes (FBTs) are a significant public health problem, especially in the countries of Eastern Europe, Africa, Latin American, and Asia (Yossepowitch et al., 2004; Marcos et al., 2008). It is estimated that 600 million people worldwide suffer from bilharzias, especially opisthorchiasis (Sripa et al., 2007; Swee 2010). Infections in South East Asia, including in Thailand, Lao-PDR, Vietnam, and Cambodia, have been found to be caused by Opisthorchis viverrini (O. viverrini) (Kaewpitoon et al., 2008).

In Thailand, approximately 7 million people are estimated to be affected by liver flukes, the highest prevalence in the world (Sornmani et al., 1984; Vatanasapt et al., 1990; Vanchai and Banchob 2000; Jongsuksuntigul and Imsomboon 2003). The epidemic has been found to differ dependant on geographical states and environmental conditions. In Thailand, infection is mostly found in the northeastern and northern regions of the country (Sripa et al., 2007; Kaewpitoon, Kaewpitoon et al., 2008; Sripa and Pairojkul 2008, Rangsin et al., 2009). Khon Kaen province, in particular, has been found to have the highest level of infection in Thailand (24.5\%), and in the world (Sriamporn et al., 2004, Sriamporn et al., 2005; Sripa 2012). In addition, liver fluke infection is a major cause 
of cholangiocarcinoma, the incidence of which is mostly found in northeastern Thailand, where 84.6 per 100,000 people are affected (Vatanasapt and Sripa 2000; Sriamporn et al., 2004).

Although attempts to prevent cholangiocarcinoma have been implemented in the past 30 years, it has been found that a widespread incidence of $O$. viverrini still persists in communities and people have not changed their consumption behaviour. As a result, liver fluke is still a major public health problem. This study of community-based health education and communication model development for opisthorchiasis prevention in highrisk areas was therefore initiated to construct a body of knowledge aimed at preventing and controlling liver fluke infection. It was designed to be relevant to the lifestyle, and social and cultural environments of communities in Thailand. The model emphasises community participation, and aims to increase the potential for selfreliance in communities, develops and strengthen the public health network, and change people's risk-taking behaviours.

The aim of this research was to study the effects of the community-based health education and communication model in preventing liver fluke infections caused by uncooked fish consumption in high-risk areas based on Khon Kaen province, Thailand.

\section{Materials and Methods}

The study consisted of three stages. Stage 1 involved a survey of the level of opisthorchiasis. The target group consisted of 390 persons.

Stage 2 covered the quasi-experimental research design, the the process of implementing the community-

Table 1. Target Group Data for those who Consumed Uncooked Fish, and those who did not Consume Uncooked Fish

\begin{tabular}{|c|c|c|c|}
\hline \multirow[t]{2}{*}{ Independent Factors } & \multicolumn{2}{|c|}{ Uncooked Fish Consumption } & $\mathrm{p}$-value \\
\hline & $\begin{array}{c}\text { Total } \\
\text { No. }(\%)\end{array}$ & $\begin{array}{c}\text { Yes } \\
\text { No. }(\%)\end{array}$ & $\begin{array}{c}\text { No } \\
\text { No. }(\%)\end{array}$ \\
\hline \multicolumn{3}{|l|}{ Gender } & 0.001 \\
\hline Male & $202(51.8)$ & $191(54.6)$ & $11(27.5)$ \\
\hline Female & $188(48.2)$ & $159(45.4)$ & $29(72.5)$ \\
\hline \multicolumn{3}{|l|}{ Age (Mean 46.01) } & 0.038 \\
\hline $20-40$ years old & $102(26.2)$ & $97(27.7)$ & $5(12.5)$ \\
\hline $41-60$ years old & $288(73.8)$ & $253(72.3)$ & $35(87.5)$ \\
\hline \multicolumn{3}{|l|}{ Educational Level } & \multirow{2}{*}{$\begin{array}{l}0.340 \\
0)\end{array}$} \\
\hline Secondary Education & $354(90.8)$ & $316(90.3)$ & \\
\hline \multicolumn{4}{|c|}{ Higher than Secondary Education } \\
\hline & $36(9.2)$ & $34(9.7)$ & $2(5.0)$ \\
\hline \multicolumn{3}{|l|}{ Occupation } & 0.515 \\
\hline Agriculture & $335(85.9)$ & $302(86.3)$ & $33(82.5)$ \\
\hline Non Agriculture & $55(14.1)$ & $48(13.7)$ & $7(17.5)$ \\
\hline \multicolumn{3}{|c|}{ Participation in Social Activity } & 0.210 \\
\hline Regular & $178(45.7)$ & $156(44.6)$ & $22(55.0)$ \\
\hline Irregular & $212(54.3)$ & $194(55.4)$ & $18(45.0)$ \\
\hline \multicolumn{3}{|l|}{ Smoking } & 0.007 \\
\hline Yes & $144(36.9)$ & $137(39.1)$ & $7(17.5)$ \\
\hline No & $246(63.1)$ & $213(60.9)$ & $33(82.5)$ \\
\hline \multicolumn{3}{|l|}{ Alcohol Consumption } & 0.000 \\
\hline Yes & $219(56.2)$ & $186(53.1)$ & $33(82.5)$ \\
\hline No & $171(43.8)$ & $164(46.9)$ & $7(17.5)$ \\
\hline
\end{tabular}

based health education and communication strategy for opisthorchiasis prevention in high-risk areas. An experimental group and a control group, each consisting of 90 persons, were established, and the study was conducted over the period May 2011-April 2012.

Stage 3 was an evaluation of the experiment using an instrument adapted from the health behaviour evaluation form in opisthorchiasis of the Department of Disease Control, Ministry of Public Health.

The target groups in the study were obtained through systematic sampling. The criterion was to select people aged between 20 and 60 years old, and who had lived in the high-risk areas for at least one year. The Chee River basin in Khon Kaen province, covering the districts of Ban-had, Ban-pai, Chonnabot, Munchakiri and Pra-yuen, was identified as having the highest level of incidence of cholangiocarcinoma (Sripa et al., 2008).

Both quantitative and qualitative data analysis were conducted. The data was analyzed using descriptive statistics, the chi-square test, the Willcoxon matched paired signed ranks test, and the Mann-Whitney U test. The research study, involved human research subjects, and as such was approved by the Khon Kaen University ethics review committee. The approval number was HE 541333.

\section{Results}

\section{Demographic Data}

The proportion of males to females in the study was almost the same, the average age being 46.01 years; for two-thirds of the sample population, the ages ranged between 41 and 60 years old. The majority of participants, $65.4 \%$, had received a primary school education. The

Table 2. Classification of Population based on Knowledge, Attitude, at-risk Behaviour as well as Stages in Behaviour Change in Relation to Opisthorchiasis

\begin{tabular}{|c|c|c|c|}
\hline \multicolumn{3}{|c|}{$(n=390$ persons $)$} & $95 \% \mathrm{CI}$ \\
\hline \multicolumn{4}{|c|}{ Levels of Knowledge and Comprehension of Opisthorchiasis } \\
\hline Low & 1 & 0.3 & $0.00-1.42$ \\
\hline Moderate & 40 & 10.3 & $7.43-13.70$ \\
\hline High & 349 & 89.5 & $86.00-92.35$ \\
\hline \multicolumn{4}{|c|}{ Levels of Attitude towards Opisthorchiasis } \\
\hline Negative & 0 & 0 & $0.00-0.94$ \\
\hline Fair & 22 & 5.6 & $3.57-8.42$ \\
\hline Positive & 368 & 94.4 & $91.58-96.43$ \\
\hline \multicolumn{4}{|l|}{ Risk Behaviour } \\
\hline Low & 203 & 52.1 & $46.97-57.09$ \\
\hline Moderate & 164 & 42.1 & $37.13-47.13$ \\
\hline High & 23 & 5.9 & $3.86-8.84$ \\
\hline \multicolumn{4}{|l|}{ Uncooked Fish Consumption } \\
\hline Yes & 350 & 89.7 & $86.19-92.49$ \\
\hline No & 40 & 10.3 & $7.51-13.81$ \\
\hline \multicolumn{4}{|l|}{ Stages of Behaviour Changes } \\
\hline Stage 1 Pre-contemplation & 215 & 55.1 & $50.04-60.14$ \\
\hline Stage 2 Contemplation & 88 & 22.6 & $18.51-27.04$ \\
\hline Stage 3 Preparation & 2 & 2.1 & $0.06-1.84$ \\
\hline Stage 4 Action & 0 & 0 & $0.00-0.94$ \\
\hline Stage 5 Maintenance & 2 & 0.5 & $0.06-1.84$ \\
\hline Stage 6 Termination & 77 & 19.7 & $15.91-24.05$ \\
\hline
\end{tabular}


Community-Based Health Education and Communication Model Development for Opisthorchiasis Prevention in Khon Kaen second order, had received an upper secondary school education. The majority of participants, $80 \%$, were agriculturists. More than $56.2 \%$ of participants drank alcohol and $36.9 \%$ smoked. It was found that most, $62.3 \%$, had never undergone stool examination for liver fluke. Moreover, $90.5 \%$ of them were used to defecating without the benefit of toilet facilities. The risk factor details of uncooked fish consumption are shown in Table 1.

The population was classified based on the level of its knowledge, attitude, and risk behaviour relating to opisthorchiasis

It was found that most of the target population, more than $89.5 \%$ (95\%CI: 86.00-92.35), had a "good" level of knowledge and comprehension of opisthorchiasis. For liver fluke caused by risk-taking behaviour in uncooked fish consumption, it was found that a majority of participants, 55.1\% (95\%CI: 50.04-60.14), did not think they should or were not interested in giving up uncooked fish consumption, which put them at Stage 1-precontemplation, based on stage of change in behaviour levels. The second order, $22.6 \%$, were at the stage where they wanted to give up consumption in the next six months which was Stage 2-contemplation. Participants who had been consumers of uncooked fish but who had stopped for more than five years, $19.7 \%$, were at the Stage 6-termination level, as shown in Table 2.

\section{Factors associated with uncooked fish consumption}

According to correlation analysis using bi-variate analysis, four factors were found to be associated with uncooked fish consumption: alcohol consumption OR 4.16 (95\% CI: 1.79-9.65), gender OR 3.17 (95\%CI: 1.53-6.54), smoking OR 3.03 (95\%CI: 1.31-7.05), and age OR 2.68 (95\%CI: 1.02-7.05). However, when these four factors were analyzed using multivariate logistic regression, it was found that only "alcohol consumption" was associated with uncooked fish consumption, and was found to be the statistically significant factor in preventing such consumption adjusted OR 0.36 (95\% CI: 0.15-0.83) p-value 0.0171, as shown in Table 3.

The process of model development for community-based health education and communication

The development of a model for a community-based health education and communication programme to change uncooked fish consumption consisted of four stages, as follows:

Stage 1: community preparation and planning for problem solving, were carried out by holding a brainstorming session on the problem - the impact of uncooked fish consumption, project participation, and advertising the intention of the study in the community.

Stage 2: community health media was produced by three major groups, including: 1) 29 village health volunteers working on various health activities with subdistrict health promotion hospitals, as well as taking care of 10-15 families; 2) popular local artists called "Mo-lum" providing recreational activities for participants during traditional community merit rituals; and 3) 14 community leaders communicating with village members on different public issues affecting them. These three groups played important roles in helping bring about behavioral change related to uncooked fish consumption.

Stage 3: health education and communication dissemination was conducted through channels that were part of the lifestyle and culture of the community, on two levels: 1) the dissemination of health education and communication at the personal level through home visits

Table 3. Analysis of Factors Associated with Uncooked fish Consumption - Crude and Adjusted Odds Ratio

\begin{tabular}{|c|c|c|c|c|c|c|}
\hline Independent Factors & $\begin{array}{l}\text { Risky Food } \\
\text { Consumption } \\
\text { Number }(\%)\end{array}$ & $\begin{array}{l}\text { No Risky Food } \\
\text { Consumption } \\
\text { Number }(\%)\end{array}$ & $\mathrm{COR}^{*}$ & $\mathrm{AOR} * *$ & $\begin{array}{c}95 \% \text { CI of } \\
\text { AOR }\end{array}$ & p-value \\
\hline \multicolumn{7}{|l|}{ Gender } \\
\hline Males & $191(54.6)$ & $11(27.5)$ & 3.17 & 1.26 & $0.65-2.44$ & 0.491 \\
\hline Females & $159(45.4)$ & $29(72.5)$ & & & & \\
\hline \multicolumn{7}{|l|}{ Age } \\
\hline $20-40$ years old & $97(27.7)$ & $5(12.5)$ & 2.68 & 1.35 & $0.78-2.34$ & 0.282 \\
\hline $41-60$ years old & $253(72.3)$ & $35(87.5)$ & & & & \\
\hline \multicolumn{7}{|l|}{ Educational Level } \\
\hline Secondary Education & $316(90.3)$ & $38(95.0)$ & 0.49 & - & - & - \\
\hline Higher than Secondary Education & $34(9.7)$ & $2(5.0)$ & & & & \\
\hline \multicolumn{7}{|l|}{ Occupation } \\
\hline Agriculture & $302(86.3)$ & $33(82.5)$ & 1.34 & - & - & - \\
\hline Non Agriculture & $48(13.7)$ & $7(17.5)$ & & & & \\
\hline \multicolumn{7}{|l|}{ Participation in Social Activity } \\
\hline Regular & $156(44.6)$ & $22(55.0)$ & 0.66 & - & - & - \\
\hline Irregular & $194(55.4)$ & $18(45.0)$ & & & & \\
\hline \multicolumn{7}{|l|}{ Smoking } \\
\hline Yes & $137(39.1)$ & $7(17.5)$ & 3.03 & 1.42 & $0.55-3.65$ & 0.464 \\
\hline No & $213(60.9)$ & $33(82.5)$ & & & & \\
\hline \multicolumn{7}{|l|}{ Alcohol Consumption } \\
\hline Yes & $186(53.1)$ & $33(82.5)$ & 4.16 & 0.36 & $0.15-0.83$ & 0.0171 \\
\hline No & $164(46.9)$ & $7(17.5)$ & & & & \\
\hline
\end{tabular}

* COR=Crude Odds Ratio; ** AOR=Adjusted Odds Ratio 
and training. Health education teaching at the personal level was implemented every two months; and 2) the dissemination of health education and communication at the community level via broadcasting towers every month.

Stage 4: a 12-month follow-up and evaluation process was undertaken after the implementation of the project. The details are shown in Figure 1.

The pre-test and post-test of community-based health education and communication

After nine months of the experiment, it was found there were significant differences in the risk level of uncooked fish consumption $(\mathrm{P}=0.011)$, and there were significant differences in behaviour levels based on stage of change assessments $(\mathrm{P}=0.002)$. It was found that $37.8 \%$ of the experimental group members were not interested in any change or were still at the pre-contemplation stage. In contrast, in the control group, $82.2 \%$ of participants were

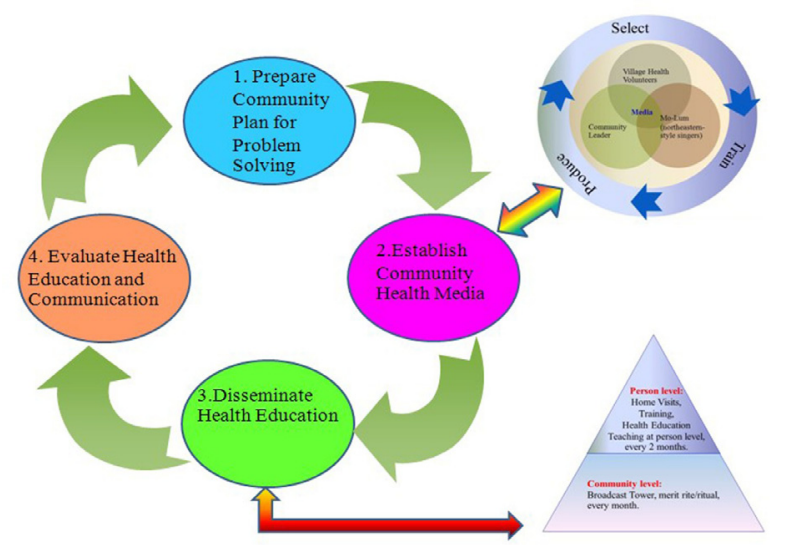

Figure 1. Process of Providing CommunityBased Health Education and Communication for Opisthorchiasis Prevention

Table 4. Comparison of Community-based Health Education and Communication for Opisthorchiasis between the Experimental Group and the Control Group, Post-test

\begin{tabular}{lcrl}
\hline Population Classification & $\begin{array}{c}\text { Experimental } \\
\text { Group } \\
\text { No. }(\%)\end{array}$ & $\begin{array}{c}\text { Control } \\
\text { Group } \\
\text { No. }(\%)\end{array}$ & p-value \\
\hline Level of Knowledge and Comprehension of Opisthorchiasis \\
Low Level & $0(0.0)$ & $0(0.0)$ & \\
Moderate Level & $4(8.9)$ & $5(11.1)$ & 0.725 \\
High Level & $41(91.1)$ & $40(88.9)$ & \\
Attitudes towards Opisthorchiasis & & & \\
Negative & $0(0.0)$ & $0(0.0)$ & \\
Fair & $6(13.3)$ & $9(20.0)$ & 0.396 \\
Positive & $39(86.7)$ & $36(80.0)$ & \\
Level of Risk Behaviour & & & \\
Low Level & $21(46.7)$ & $19(42.2)$ & 0.011 \\
Moderate & $24(53.3)$ & $18(40.0)$ & \\
High Level & $0(0.0)$ & $8(17.8)$ & \\
Behaviour Level based on Stage of Change & & \\
Stage 1 Pre-contemplation & $17(37.8)$ & $37(82.2)$ & 0.002 \\
Stage 2 Contemplation & $5(11.1)$ & $2(4.4)$ & \\
Stage 3 Preparation & $6(13.3)$ & $2(4.4)$ & \\
Stage 4 Action & $8(17.8)$ & $4(8.9)$ & \\
Stage 5 Maintenance & $3(6.7)$ & $0(0.0)$ & \\
Stage 6 Termination & $6(13.3)$ & $0(0.0)$ & \\
\hline
\end{tabular}

not interested in any change. However, it was found that there were no significant differences in knowledge and attitude levels between the experimental group and control group. The details are shown in Table 4.

\section{Discussion}

Uncooked Fish Consumption Behaviour: It was found that most of the survey population had knowledge of o pisthorchiasis and a good attitude towards its prevention. This finding was supported by research studies of liver fluke in the northeastern region of Thailand where it has been found that more than half of the population has a high level of knowledge, and one-third of the population has a good attitude towards opisthorchiasis prevention (Thaewnongiew et al., 2014). However, according to the findings of this study, $90 \%$ of the population still consumed uncooked fish. As a result, liver fluke infection is still a major public health problem in the northeastern region. A recent study of people in the area surrounding Kang-la-wa water source, Khon Kaen province, found that $61.85 \%$ suffered from liver fluke infection (Sripa et al., 2008; Sripa et al., 2015, Thaewnongiew et al., 2014). Stopping people from consuming uncooked fish in highrisk areas is therefore still a major public health problem.

Risk Factors in Uncooked Fish Consumption: According to bi-variate analysis, there is a relationship between alcohol consumption, gender, smoking and age, and uncooked fish consumption. However, there was no relationship when multivariate logistic regression was used. This was not supported by a study of risk factors for opisthorchiasis in the upper northeastern region, which found that males had higher levels of opisthorchiasis than females at 1.2 (95\%CI: 1.01-1.44); persons aged over 50 years old were more at risk of suffering from opisthorchiasis 1.6 (95\%CI: 1.09-2.24); and living near a water source increased the risk of opisthorchiasis to 1.5 (95\%CI: 1.26-1.73) (Thaewnongiew et al., 2014). However, according to the research findings, drinking alcohol was a preventive factor in uncooked fish consumption 0.36 (95\% CI: 0.15-0.83). This finding was the opposite of other studies in the northeastern region, which found that alcohol consumption was a risk factor for liver fluke, with OR 5.3 (95\% CI:1.2-23.0) (Yeoh et al., 2015). It is generally accepted that opisthorchiasis is caused by uncooked fish consumption, but exactly which factors affect uncooked fish consumption is unclear. Although the programme of this study was conducted over an extended period of time, uncooked fish consumption continued to be a problem, and, consequently, the problem would appear to resist efforts to solve it efficiently.

The Process of Community-Based Health Education and Communication for Opisthorchiasis Prevention: The model for behavioral change in uncooked fish consumption of this study, will be based on population classification according to risk factors, cultural capital, and human resources available to implement the media production process as well as media persons responsible for communicating and providing information designed to change the target group's behaviour. After nine months of implementation, it was found that there were 
Community-Based Health Education and Communication Model Development for Opisthorchiasis Prevention in Khon Kaen significant differences in the level of risk of uncooked fish consumption between the experimental group and the control group. Furthermore, there were significant differences in the levels of behaviour based on stage of change in a positive direction. This was supported by research studies in community-based health education and communication programmes, implemented by teachers and volunteers (Sota et al., 2011; Duangsong et al., 2013). It is possible that the success of the initiative was due to three main factors: the media process and the resulting communication with people through community channels and facilities, for instance the broadcast tower; taking into account the cultural background, e.g. community merit rites; and the use of human resources in the community, including community volunteers to disseminate information, Mo-lum (northeastern-style singers), and community leaders as a means of accessing community members and locality, as they were familiar to the people and relevant to the lifestyle of the community. As a result of these measures and use of selected personnel, people were able to effectively perceive the information and news. Besides, target group classification based on stage of change assessment provided an opportunity for individualized intervention. For instance, knowledge can be targeted based on the level of target group behaviour relating to uncooked fish consumption. Community capital based on cultural sensitivity was used for the development of technology for communication media to solve the problem of uncooked fish consumption in order to prevent illness and death from cholangiocarcinoma, the incidence of which is likely to increased every year (Kamsa-ard et al., 2011).

Consequently, this study proposes recommendations for health education and communication for opisthorchiasis prevention in the population: community groups or organizations should be actively encouraged to participate in activity management, using existing cultural and communication media in the community, for example, Mo-lum (northeastern-style singers), public health volunteers in the villages, and community leaders. Workshops on the development of media skills and resources in the community were valuable avenues for active community participation. In addition, the guidelines for solving the problem of raw fish eating should have regard for community beliefs and behaviours. The concept of stage of change at the personal level can be a guide to behavioral change activities appropriate to each person. Longitudinal studies as a follow up to further assess raw fish consumption should be conducted to gain a deeper understanding of the risk behaviours, and to further generate effective strategies to solve the problem permanently.

\section{Acknowledgements}

The authors would like to thank the participants in the study. This research was supported by the Khon Kaen University Graduate Research Fund for Academic Year 2012, no. 55122103 .

\section{References}

Duangsong R,Promthet S, Thaewnongiew K (2013). Development of a community-based approach to opisthorchiasis control. Asian Pac J Cancer Prev, 14, 7039-43.

Jongsuksuntigul P, Imsomboon T (2003). Opisthorchiasis control in Thailand. Actatropica, 88, 229-32.

Kaewpitoon N, Kaewpitoon SJ, Pengsaa P(2008). Opisthorchiasis in Thailand: review and current status. World J Gastroenterol, 14, 2297-302.

Kaewpitoon N, Kaewpitoon SJ, Pengsaa P, et al (2008). Opisthorchisviverrini: the carcinogenic human liver fluke. World J Gastroenterol, 14, 666-74.

Kamsa-Ard S, Wiangnon S, Suwanrungruang K, et al (2011). Trends in liver cancer incidence between 1985 and 2009, Khon Kaen, Thailand: cholangiocarcinoma. Asian Pac J Cancer Prev, 12, 2209-13.

Marcos LA, Terashima A, Gotuzzo E (2008). Update on hepatobiliary flukes: fascioliasis, opisthorchiasis and clonorchiasis. Curr Opin Infect Dis, 2, 523-30.

Rangsin R, Mungthin M, Taamasri P, et al (2009). Incidence and risk factors of Opisthorchis viverrini infections in a rural community in Thailand. The Am J Trop Med Hyg, 81, 152-5.

Sornmani S, Schelp FP, Vivatanasesth P, et al (1983). A pilot project for controlling $O$. viverrini infection in NongWai, Northeast Thailand, by applying praziquantel and other measures. Arzneimittel-Forschung, 34, 1231-4.

Sota C, Sithithaworn P, Duangsong R, et al (2011). The effectiveness of health education program for liver fluke preventing behavior by using hand book and vcd in primary school students. The Social Sciences, 6, 136-40.

Sriamporn S, Parkin DM, Pisani P, et al (2005). A prospective study of diet, lifestyle, and genetic factors and the risk of cancer in KhonKaen Province, northeast Thailand: description of the cohort. Asian Pac J Cancer Prev, 6, 295-303.

Sriamporn S, Pisani P, Pipitgool V, et al (2004). Prevalence of Opisthorchis viverrini infection and incidence of cholangiocarcinoma in Khon Kaen, Northeast Thailand. Trop Med Int Health, 9, 588-94.

Sripa B (2012). Global burden of food-borne trematodiasis.The Lancet infectious diseases, 12, 171-2.

Sripa B, Kaewkes S, Sithithaworn P, et al (2007). Liver fluke induces cholangiocarcinoma. PLoS Med, 4, 201.

Sripa B, Laha T, et al (2008). "Opisthorchis viverrini infection and cholangiocarcinoma update from a endemic area in northeast Thailand." 2015, from http://www.icssc.org/ documents/presentations/irid2008abstracts/29-brindley.pdf.

Sripa B, Pairojkul C (2008). Cholangiocarcinoma: lessons from Thailand. Curr Opin Gastroenterol, 24, 349-56.

Sripa B, Tangkawattana S, Laha T, et al (2015). Toward integrated opisthorchiasis control in Northeast Thailand: The Lawa project. Actatropica, 141, 361-7.

Swee Chong Quek (2010). Cancer can be prevented too : Protection against-causing infections. World Cancer Campaign 2010. Geneva, Switzerland, 40-8.

Thaewnongiew K, Singthong S, Kutchamart S, et al (2013). Prevalence and risk factors for Opisthorchis viverrini infections in upper Northeast Thailand. Asian Pac J Cancer Prev, 15, 6609-12.

Vatanasapt V, Sripa B (2000). Liver cancer in Thailand : epidemiology, diagnosis and control. KhonKaen, Thailand, Siriphan Press, 188.

Vatanasapt V, Uttaravichien T, Mairiang P, et al (1990). Cholangiocarcinoma in north-east Thailand. The Lancet, 335, 116-7.

WHO (2004). Joint WHO/FAO workshop on foodborne 
Paitoon Promthet et al

trematode infections in Asia HaNoi, Viet Nam. World Health Organization. Manila, Philippines.

Yeoh KW, Promthet S, Sithithaworn P, et al (2014). Reexamination of Opisthorchis viverrini infection in Northeast Thailand. Asian Pac J Cancer Prev, 16, 3413-8.

Yossepowitch O, Gotesman T, Assous M, Marva E,Zimlichman $\mathrm{R}$, and Dan, M (2004). Opisthorchiasis from imported raw fish. Emerg Infect Dis, 10, 2122-6. 